\title{
DynamicSainT
}

Jilid. IV No. 2., Oktober 2019

\section{HUBUNGAN KECEPATAN, VOLUME DAN KEPADATAN LALULINTAS DI JALAN DR. RATULANGI (DEPAN CITY MARKET PALOPO) MENGGUNAKAN MODEL GREENSHIELDS}

\author{
Abdias Tandi Arrang \\ Program Studi Teknik Sipil, Fakultas Teknik, Universitas Kristen Indonesia Toraja. \\ Jl. Nusantara No. 12,Makale, Tana Toraja, Sulawesi Selatan
}

\begin{abstract}
ABSTRAK
Terbangunnya City Market Palopo sebagai salah satu pusat perbelanjaan di Kota Palopo memberikan dampak pada bertambahnya volume lalulintas di Jalan Dr. Ratulangi, di mana jalan tersebut merupakan salah satu jalan utama yang menjadi penghubung antara Makassar sebagai ibu kota Propinsi Sulawesi Selatan ke daerah seperti Luwu Utara, Luwu Timur bahkan ke Propinsi Sulawesi Tengah, dan Sulawesi Tenggara. Adanya peningkatan volume lalu lintas akan menyebabkan berubahnya perilaku lalu lintas. Secara teoritis terdapat hubungan yang mendasar antara volume (flow) dengan kecepatan (speed) serta kepadatan (density). Penelitian dilakukan dengan survey arus, kecepatan dan mengambil data geometrik pada lokasi penelitian. Data kemudian diolah dan dianalisis dengan metode Greeshields. Dari analisis tersebut diperoleh persamaan hubungan antara volume dan kepadatan adalah $Q=30.766 \mathrm{D}-0.081 \mathrm{D}^{2}$, sementara persamaan hubungan antara kecepatan dan kepadatan adalah $S=30.766$ - $0.081 \mathrm{D}$ dan persamaan hubungan antara kecepatan dan volume adalah $Q=$ $377.144-12.258 S^{2}$. Analisis menunjukkan bahwa grafik hubungan antara arus, kecepatan dan kepadatan sesuai dengan model Greenshields.
\end{abstract}

Kata Kunci: Kecepatan, volume, kepadatan, lalu lintas dan Greenshields

\section{PENDAHULUAN}

Pembangunan sebuah pusat perbelanjaan akan selalu berdampak pada lalu lintas di sekitarnya. Kehadiran City Market sebagai pusat perbelanjaan di Kota Palopo menarik pengunjung dari berbagai daerah disekitar Palopo misalnya, Luwu, Luwu Utara, Luwu Timur bahkan dari Toraja Utara dan Tana Toraja. Hal ini memberikan pengaruh besar pada lalu lintas di Jl, Dr. Ratulangi di mana City Market berada. Untuk mengetahui bagaimana kondisi parameter lalu lintas saat ini utamanya terkait kecepatan, volume, kepadatan dan hubungan antara ketiga parameter tersebut maka perlu dilakukan suatu penelitian.

\section{KAJIAN PUSTAKA}

\subsection{Parameter Lalu Lintas}

Analisis karakteristik untuk suatu ruas jalan dapat dilakukan dengan mempelajari hubungan matematis antara kecepatan $(S)$, kepadatan $(D)$ dan volume $(V)$ lalu lintas yang terjadi pada ruas jalan tersebut. Menurut Tamin (2008), hubungan matematis antara kecepatan, kepadatan dan volume lalu lintas dapat dinyatakan dengan persamaan berikut :

$$
\mathrm{V}=\mathrm{D} \cdot \mathrm{S}
$$

Dimana

$\mathrm{V}=$ volume lalu lintas kendaraan/jam)

$\mathrm{D}=$ kepadatan lalu lintas kendaraan $/ \mathrm{km}$ )

$\mathrm{S}=\operatorname{kecepatan}(\mathrm{km} / \mathrm{jam})$

\subsection{Ekivalen Mobil Penumpang}

Dalam Leksmono (2016) disebutkan bahwa satuan mobil penumpang (SMP) 


\section{DynamicSainT}

Jilid. IV No. 2., Oktober 2019

adalah suatu ukuran yang menunjukkan ruang jalan yang dipergunakan oleh suatu jenis kendaraan serta kemampuan manuvernya.

Ekivalen mobil penumpang (EMP) untuk masing-masing tipe kendaraan tergantung pada tipe jalan dan arus lalu lintas total dinyatakan dalam 1 jam.

Tabel 1. Ekivalensi mobil penumpang (EMP) untuk jalan perkotaan tak terbagi

\begin{tabular}{|c|c|c|c|c|}
\hline \multirow{4}{*}{ Tipe Jalan } & \multirow{4}{*}{$\begin{array}{c}\text { Arus lalu } \\
\text { lintas per } \\
\text { jalur } \\
(\text { Kend/jam })\end{array}$} & \multicolumn{3}{|c|}{ EMP } \\
\hline & & \multirow{3}{*}{$\mathrm{HV}$} & \multicolumn{2}{|c|}{$\mathrm{MC}$} \\
\hline & & & \multicolumn{2}{|c|}{$\begin{array}{l}\text { Lebar lajur } \\
\text { LL (m) }\end{array}$} \\
\hline & & & $\leq 6$ & $>6$ \\
\hline \multirow{2}{*}{$\begin{array}{c}\text { Dua Lajur } \\
\text { Tak } \\
\text { Terbagi } \\
\text { (2/2 UD) }\end{array}$} & $<800$ & 1,3 & 0,5 & 0,4 \\
\hline & $\geq 1800$ & 1,2 & 0,35 & 0,25 \\
\hline \multirow{2}{*}{$\begin{array}{c}\text { Empat } \\
\text { Lajur Tak } \\
\text { terbagi (4/2 } \\
\text { UD) }\end{array}$} & $<1800$ & 1,3 & & \\
\hline & $\geq 1800$ & 1,2 & & \\
\hline
\end{tabular}

Sumber : MKJI 1997

Nilai SMP untuk tiap jenis kendaraan berbeda berdasarkan koefisien ekivalen mobil penumpang (EMP).

Perhitungan dilakukan per satuan jam untuk satu atau lebih periode, misalnya didasarkan pada kondisi arus lalulintas rencana jam puncak pagi, siang, dan sore.

Perhitungan volume lalu lintas dapat dihitung dengan menggunakan persamaan (2).

$\mathrm{Q}_{\mathrm{Tot}}=\sum Q_{i} \cdot \mathrm{EMP}_{i}$

Dimana :

$\mathrm{Q}_{\mathrm{Tot}}=$ Volume lalu lintas $($ smp/jam $)$.

$\mathrm{Q}_{\mathrm{i}} \quad=$ Volume kendaraan menurut jenis kendaraan

$\mathrm{EMP}_{\mathrm{i}}=$ Ekivalen kendaraan penumpang menurut jenis kendaraan

\subsection{Karakteristik Lalu Lintas}

Karakteristik lalu lintas

menjelaskan arus secara kuantitatif dalam kaitannya dengan volume, kecepatan, kepadatan lalu lintas serta hubungannya dengan waktu maupun jenis kendaraan yang menggunakan ruang jalan yang diperlukan untuk menjadi acuan dalam perencanaan lalu lintas.

Arus dan volume lalu lintas pada suatu jalan biasanya diukur berdasarkan jumlah kendaraan yang melalui suatu titik selama selang waktu tertentu. Volume ini diukur dengan cara manual.

Menurut Morlok (1988), perhitungan dapat dilakukan untuk kendaraan pada satu jalur gerak atau pada banyak jalur gerak yang sejajar dan dapat juga merupakan jumlah kendaraan yang bergerak pada satu arah ataupun pada semua arah. Berdasarkan penyesuaian kendaraan terhadap satuan mobil penumpang volume lalu lintas dapat dihitung dengan persamaan (3).

$Q=\frac{n}{T}$

Dimana :

$\mathrm{Q}=$ Volume lalu lintas (smp/jam).

$\mathrm{n}=$ Jumlah kendaraan yang melewati titik tersebut dalam waktuinterval waktu pengamatan.

$\mathrm{T}=$ Interval waktu pengamatan.

Kecepatan didefinisikan sebagai laju dari suatu pergerakan kendaraan dihitung dalam jarak per satuan waktu. Kecepatan lalu lintas pada suatu lokasi jalan tergantung pada beberapa faktor yang berhubungan dengan kondisi daerah setempat. Besaran ini sangat bervariasi tiap jam per hari, pada setiap bulan per tahun dan karakternya berubah-ubah. Karakteristik kecepatan kendaraan 


\section{DynamicSainT}

Jilid. IV No. 2., Oktober 2019

diwaktuwaktu sibuk dengan waktu-waktu tidak sibuk pada jalur jalan seringkali berbeda dari waktu ke waktu. Perhitungan kecepatan lalu lintas dapat dihitung dengan menggunakan persamaan :

$S=\frac{T T}{L}$

Dimana :

$\mathrm{S}=$ Kecepatan rata-rata ruang $(\mathrm{km} / \mathrm{jam})$

$\mathrm{L}=$ Panjang segmen jalan $(\mathrm{km})$

$\mathrm{TT}=$ waktu tempuh rata-rata $(j a m)$

Karakteristik arus lainnya yang penting adalah kepadatan. Kepadatan adalah rata-rata jumlah kendaraan per satuan panjang jalan. Kepadatan juga dapat di definisikan sebagai jumlah kendaraan yang menempati suatu panjang jalan atau lajur, secara umum dapat diekspresikan dalam kendaraan per mil (vpm) atau kendaraan per mil per lane (vpmpl).

Kepadatan sulit di ukur secara langsung di lapangan melainkan di hitung dari nilai kecepatan dan arus dengan menggunakan persamaan :

$D=\frac{Q}{S}$

Dimana :

$\mathrm{D}=\operatorname{Kepatan}$ kendaraan $(\mathrm{kend} / \mathrm{m})$

$\mathrm{Q}=$ Volume lalulintas (Smp/Jam)

$\mathrm{S}$ = Kecepatan kendaraa Rata-rata (Km/Jam)

\subsection{Model Greenshields}

Metode Greenshields adalah salah satu model yang digunakan untuk mempresentasikan hubungan matematis antara volume, kecepatan dan kepadatan lalu lintas. Metode Greenshields merumuskan bahwa hubungan matematis antara kecepatan - kepadatan diasumsikan linear (Tamin, 2000),
$S=S_{f f}-\frac{S_{f f}}{D_{j}} . D$

Dimana :

$\mathrm{S}=\operatorname{Kecepatan}(\mathrm{km} / \mathrm{jam})$

$\mathrm{S}_{\mathrm{ff}}=$ Kecepatan pada saat kondisi lalulintas sangat rendah atau pada kondisi kepadatan mendekati nol atau kecepatan mendekati nol atau kecepatan volume bebas $(\mathrm{km} / \mathrm{jam})$

$\mathrm{D}_{\mathrm{j}}=$ Kepadatan pada kondisi volume lalulintas macet total $(\mathrm{kend} / \mathrm{km}$ )

\subsection{Analisa Regresi Linear}

Model volume lalulintas yang umum digunakan untuk menentukan karakteristik seperti kecepatan dan kepadatan adalah analisa regresi. Analisa ini digunakan untuk meminimalkan nilai kuadrat antar observasi dan nilai perkiraan dari variabel tidak bebas.

Bila variabel tidak bebas linier terhadap variabel bebas maka hubungan tersebut dikenal dengan analisa regresi linier. Bila variabel tidak bebas y dan variabel bebas $\mathrm{x}$ mempunyai hubungan linear maka fungsi regresi seperti pada persamaan (7) dan (8).

$$
\begin{aligned}
& B=\frac{n \sum X Y-\sum X \sum Y}{n \sum_{x^{2}}-\left(\sum x\right)^{2}} \\
& A=\bar{Y}-B \bar{X}
\end{aligned}
$$

Dimana:

$n=$ Jumlah dari data yang di peroleh.

$\Sigma \mathrm{x}=$ Jumlah Observasi ke $\mathrm{i}$ untuk $\mathrm{x}$

$\Sigma \mathrm{y}=$ Jumlah Observasi ke i untuk y

a) Hubungan Kecepatan - Kepadatan

Hubungan antara Kecepatan dan kepadatan secara linier menurut Greenshields seperti pada persamaaan (9). 


\section{DynamicSainT}

Jilid. IV No. 2., Oktober 2019

$$
S=S_{f f}-\frac{S_{f f}}{D_{j}} \cdot D
$$

b) Hubungan Volume - Kecepatan

Analisis hubungan volume dan kecepatan merupakan fungsi parabolik Dengan menggunakan persamaaan (10).

$$
\begin{aligned}
& Q=D_{j} . S- \\
& \frac{D_{j}}{S_{f f}} \cdot S^{2} \ldots \ldots
\end{aligned}
$$

c) Hubungan Volume - Kepadatan

Analisis hubungan volume dan kepadatan juga merupakan fungsi parabolic digunakan persamaaan (11):

$$
Q=D \cdot S_{f f}-\frac{S_{f f}}{D_{j}} \cdot S^{2}
$$

Kepadatan maksimum diperoleh dengan menggunakan persamaan (12)

$$
D_{m}=\frac{D_{j}}{2}
$$

Kecepatan saat volume maksimum didapat dengan menggunaakan persamaan (13).

$$
S_{m}=\frac{S_{f f}}{2}
$$

Volume maksimum di dapat dengan menggunakan persamaan (14):

$$
V_{m}=\frac{D_{i} \cdot S_{f f}}{4}
$$

\subsection{Model Hubungan Grafis antara Kecepatan, Volume dan Kepadatan}

Hubungan antara kecepatan, volume dan kepadatan dapat digambarkan seara grafis dengan menggunakan persamaan metematis yang merupakan persamaan dasar dari pergerakan arus lalulintas. Gambar 2.1 memperlihatkan saling keterkaitan antara variable kecepatan, volume dan kepadatan dari suatu pergerakan arus lalulintas.

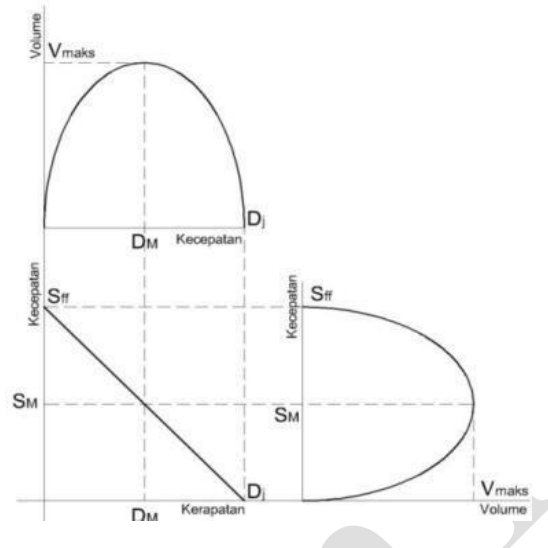

Gambar 2.1 Hubungan matematis antar volume, kecepatan dan kepadatan (Tamin, 2000)

\section{METODOLOGI}

Penelitian dilakukan dengan pengumpulan data arus dan kecepatan lalu lintas melalui survey langsung di lapangan. Survey dilakukan selama 7 (tujuh) hari, untuk menggambarkan kondisi lalu lintas selama 1 (satu) minggu, dan mulai dari pukul 06.00 21.00, di mana waktu tersebut adalah waktu lalu lintas yang padat di Jl. Dr. Ratulangi. Alur penelitan dapat dilihat pada gambar 3.1.

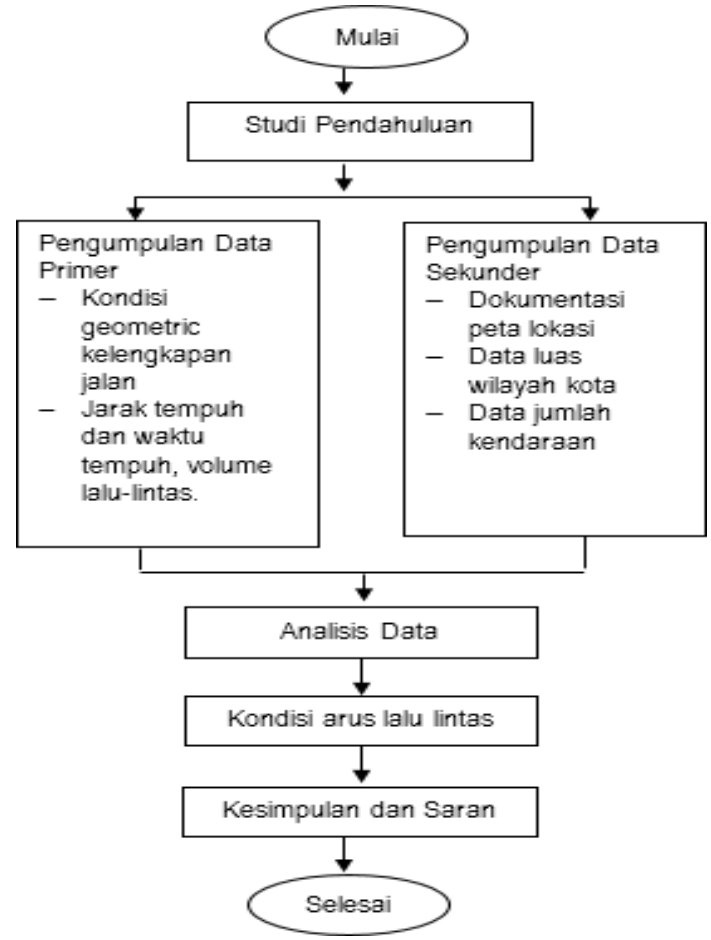

Gambar 3.1. Bagan Alur Penelitian 


\section{DynamicSainT}

Jilid. IV No. 2., Oktober 2019

\section{HASIL DAN PEMBAHASAN}

\subsection{Analisis Karakteristik dan Geometrik Jalan}

Dari pengamatan secara visual pada ruas jalan DR. Ratulangi diperoleh data sebagai berikut :

a) Jalan DR. Ratulangi merupakan jalan perkotaan.

b) Arus kendaraan terbesar terjadi pada hari Senin (sebagai hari sibuk).

c) Tipe arus lalu lintas adalah 2 lajur 2 arah tak terbagi (2/2 UD).

Hasil pengukuran geometrik jalan di tampilkan pada tabel 2.

Tabel 2 : Data Geometrik pada ruas J1. Dr. Ratulangi Palopo

\begin{tabular}{|l|r|}
\hline $\begin{array}{l}\text { Panjang jalan yang } \\
\text { diamati }\end{array}$ & $500 \mathrm{~m}$ \\
\hline Lebar lajur & $2 \times 4,5 \mathrm{~m}$ \\
\hline Lebar bahu jalan & $1 \mathrm{~m}$ \\
\hline Lebar perkerasan & $9 \mathrm{~m}$ \\
\hline
\end{tabular}

\subsection{Analisis Volume Lalu Lintas}

Hasil survey volume lalu lintas di lokasi penelitian setelah diolah dengan menggunakan persamaan (2) diperoleh hasil seperti pada gambar 4.1.

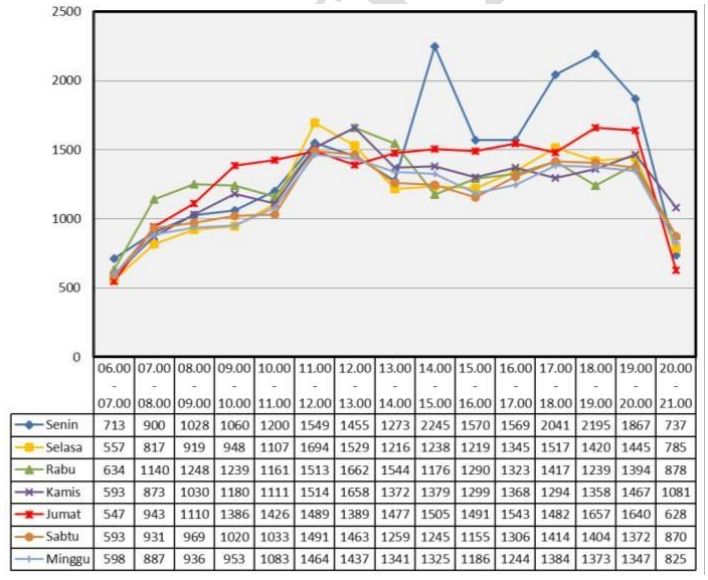

Gambar 4.1: Grafik volume lalu lintas di lokasi penelitian (Jl. Dr. Ratulangi)
Berdasarkan grafik pada Gambar 4.1., volume kendaraan tertinggi terjadi pada hari Senin pukul 14.00 dan 18.00 wit

\subsection{Analisis Kecepatan Lalu Lintas}

Analisis pada data kecepatan lalu lintas pada lokasi penelitian setelah dioleh dengan menggunakan persamaan...... diperoleh hasil seperti pada Gambar 4.2

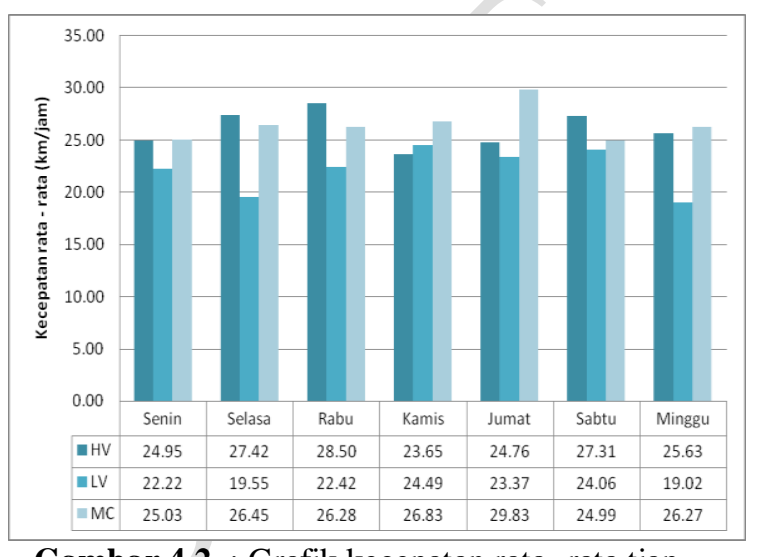

Gambar 4.2 : Grafik kecepatan rata -rata tiap jenis kendaraan $(\mathrm{km} / \mathrm{jam})$ di lokasi penelitian ( $\mathrm{Jl}$. Ratulangi)

Dari grafik kecepatan diatas dijelaskan bahwa

1. Kecepatan maksimum kendaraan berat (HV) pada saat pengamatan sebesar 26.90 $\mathrm{km} / \mathrm{jam}$ terjadi pada hari Jumat, sedangkan kecepatan minimum terjadi pada hari Kamis sebesar 23.16 km/jam.

2. Kecepatan maksimum kendaraan Ringan (LV) terjadi pada hari Rabu sebesar 26.06 $\mathrm{km} / \mathrm{jam}$, sedangkan kecepatan minimum kendaraan sebesar $17.29 \mathrm{~km} / \mathrm{jam}$ terjadi pada hari Senin

3. Kecepatan maksimum kendaraan sepeda motor (MC) terjadi pada hari Selasa sebesar $31.89 \mathrm{~km} / \mathrm{jam}$, sedangkan kecepatan minimum kendaraan sebesar $23.75 \mathrm{~km} / \mathrm{jam}$ terjadi pada hari Sabtu.

\subsection{Analisis Kepadatan Lalu Lintas}

Perhitungan kepadatan kendaraan dapat dihitung dengan menggunakan persamaan (5), selengkapnya hasil perhitungan dapat dilihat pada Tabel 3 . 


\section{DynamicSainT}

Jilid. IV No. 2., Oktober 2019

Tabel 3 : Data kepadatan lalu lintas di Lokasi Peneltian (Jl. Dr. Ratulangi)

\begin{tabular}{|l|c|c|c|}
\hline $\begin{array}{c}\text { Hari } \\
\text { Pengamatan }\end{array}$ & $\begin{array}{c}\text { Volume } \\
\text { (smp/jam) }\end{array}$ & $\begin{array}{c}\text { Kecepatan } \\
\text { (km/jam) }\end{array}$ & $\begin{array}{c}\text { Kepadatan } \\
\text { (smp/km) }\end{array}$ \\
\hline Senin & 1425 & 22.97 & 62.05 \\
\hline Selasa & 1182 & 26.06 & 45.36 \\
\hline Rabu & 1249 & 26.61 & 46.93 \\
\hline Kamis & 1247 & 24.36 & 51.19 \\
\hline Jumat & 1320 & 26.09 & 50.59 \\
\hline Sabtu & 1169 & 23.87 & 48.98 \\
\hline Minggu & 1162 & 26.74 & 43.46 \\
\hline Rata - Rata & & & 49.79 \\
\hline
\end{tabular}

Sumber: Hasil Penelitian

\subsection{Analisis Hubungan antara Volume, Kecepatan dan Kerapatan \\ Perhitungan hubungan Volume,} Kecepatan dan Kepadatan lalu lintas dapat dihitung menggunakan persamaan (7) dan (8). Sehingga diperoleh nilai :

$$
\begin{aligned}
\mathrm{A} & =\mathrm{S}_{\mathrm{ff}} \\
\mathrm{S}_{\mathrm{ff}} & =\frac{A}{B}
\end{aligned}
$$

Dengan menggunakan nilai $S_{\mathrm{ff}}$ dan $\mathrm{D}_{\mathrm{j}}$, dan menggunakan persamaan (9), maka dapat ditentukan hubungan matematis antar parameter. Tabel 4. memperlihatkan perhitungan untuk jalan DR. Ratulangi dengan menggunakan metode Greenshields.

Tabel 4 . Data perhitungan di Lokasi Peneltian

\begin{tabular}{|c|c|c|c|c|}
\hline \multirow{2}{*}{$\begin{array}{c}\text { Hari } \\
\text { Penga } \\
\text { matan }\end{array}$} & \multirow{2}{*}{$\begin{array}{c}\text { Arus (V) } \\
\mathbf{A}\end{array}$} & \multirow{2}{*}{$\begin{array}{c}\text { Kecepatan } \\
\text { (S) }=\text { Y B B }\end{array}$} & $\begin{array}{c}\text { Kepadatan } \\
\text { (D) }=\mathrm{X}\end{array}$ & $x^{2}$ \\
\hline & & & $\mathbf{C}=\mathbf{A} / \mathbf{B}$ & $D=C^{2}$ \\
\hline Senin & 2245 & 22.97 & 97.752 & 9555.391 \\
\hline Selasa & 1694 & 26.06 & 65.008 & 4226.024 \\
\hline Rabu & 1662 & 26.61 & 62.452 & 3900.279 \\
\hline Kamis & 1658 & 24.36 & 68.064 & 4632.678 \\
\hline Jumat & 1657 & 26.09 & 63.500 & 4032.2237 \\
\hline Sabtu & 1491 & 23.87 & 62.475 & 3903.083 \\
\hline Minggu & 1464 & 26.74 & 54.752 & 2997.833 \\
\hline Jumlah & 11871 & 176.70 & 474.002 & 33247.512 \\
\hline & ta-rata & 25.242 & 67.715 & \\
\hline
\end{tabular}
(Jl. Dr. Ratulangi) metode Greenshields

Sumber: Hasil Penelitian

$$
\Sigma \mathrm{x}=474.002
$$

$$
\begin{aligned}
\Sigma \mathrm{y} & =176.70 \\
\Sigma \mathrm{xy} & =11871 \\
\Sigma \mathrm{x}^{2} & =33247.512
\end{aligned}
$$

Menentukan nilai $S_{\mathrm{ff}}$ dan $\mathrm{D}_{\mathrm{j}}$ menggunakan persamaan (7) dan (8) sebagai berikut :

$$
\begin{aligned}
\mathrm{B} & =\frac{n \sum x y-\sum x \sum y}{n \sum x^{2}-\left(\sum x\right)^{2}} \\
& =\frac{(7) \times(11871)-(474.002) \times(176.70)}{(7) \times(33247.512)-(474.002)^{2}} \\
& =\mathbf{- 0 . 0 8 1 6}
\end{aligned}
$$$$
\mathrm{A}=A=\bar{Y}-B \bar{X}
$$$$
=(25.2422)-(-0.0816)(67.7146)
$$$$
=30.7661
$$

Sehingga dengan menggunakan persamaan (9) diperoleh nilai :

$$
\begin{aligned}
& \mathrm{A}=\mathrm{S}_{\mathrm{ff}}=30.7661 \mathrm{~km} / \mathrm{jam} \\
& \mathrm{D}_{\mathrm{j}}=-\frac{A}{B}=\frac{30.766}{(-0.0816)} \\
& =377.144 \mathrm{smp} / \mathrm{jam}
\end{aligned}
$$

a) Hubungan Volume - Kepadatan

Dengan menggunakan persamaaan (11) dapat dihitung hubungan volume kepadatan seperti di bawah ini :

$$
\begin{aligned}
\mathrm{Q} & =D . S_{f f}-\frac{S_{f f}}{D_{j}} \cdot S^{2} \\
& =30.76612 . D-\left(\frac{30.76612}{377.144}\right) \cdot D^{2} \\
\mathbf{Q} & =\mathbf{3 0 . 7 6 6} \mathbf{D}-\mathbf{0 . 0 8 1} \mathbf{D}^{2}
\end{aligned}
$$

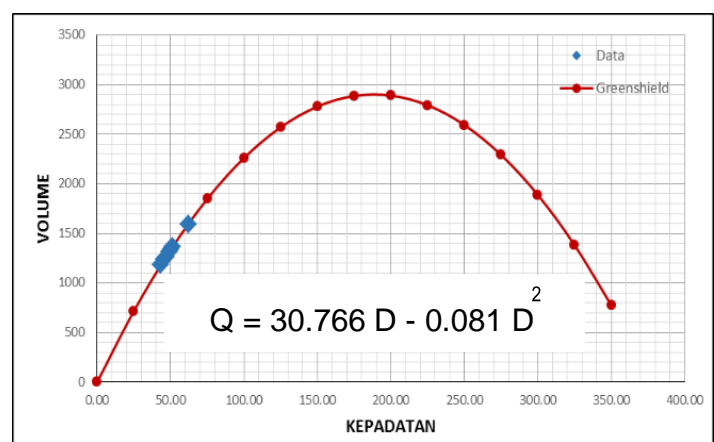

Gambar 4.3 : Grafik Hubungan antara Volume dan kepadatan di lokasi penelitian (Jl. Dr. Ratulangi) 


\section{DynamicSainT}

Jilid. IV No. 2., Oktober 2019

b) Hubungan Kecepatan - Kepadatan

Dengan menggunakan persamaaan (9)

dapat dihitung hubungan kecepatan kepadatan seperti dibawah ini:

$$
\begin{aligned}
\mathrm{S} & =S_{f f}-\frac{S_{f f}}{D_{j}} \cdot D \\
\mathrm{~S} & =30.76612-\left(\frac{30.76612}{377.144}\right) \cdot D \\
\mathbf{S} & =\mathbf{3 0 . 7 6 6 - 0 . 0 8 1 \mathrm { D }}
\end{aligned}
$$

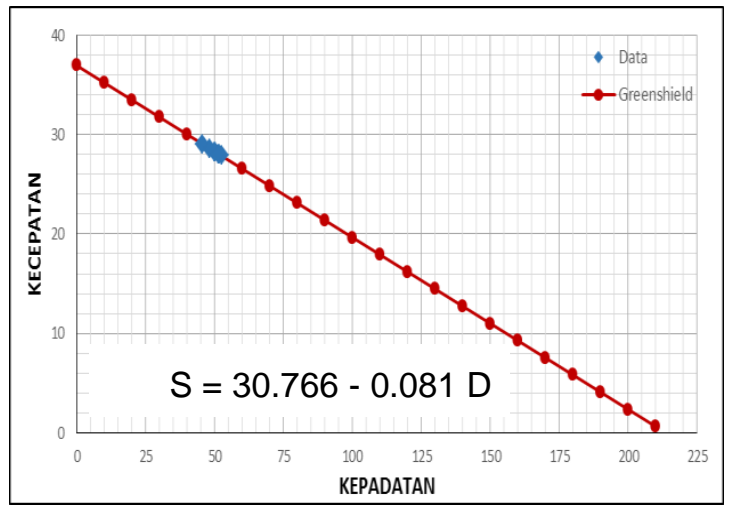

Gambar 4.4 : Grafik Hubungan antara

Kecepatan dan kepadatan di lokasi penelitian (Jl. Dr. Ratulangi)

c) Hubungan Kecepatan - Volume

Dengan menggunakan persamaaan

(10) dapat dihitung hubungan volume kecepatan seperti dibawah ini :

$$
\begin{aligned}
& \mathrm{Q}=D_{j} \cdot S-\frac{D_{j}}{S_{f f}} \cdot S^{2} \\
& \mathrm{Q}=214.296 S-\left(\frac{214.297}{36.935}\right) \cdot S^{2} \\
& \mathbf{Q}=\mathbf{2 1 4 . 2 9 6} \mathbf{S}-\mathbf{5 . 7 9 3} \mathbf{S}^{2}
\end{aligned}
$$

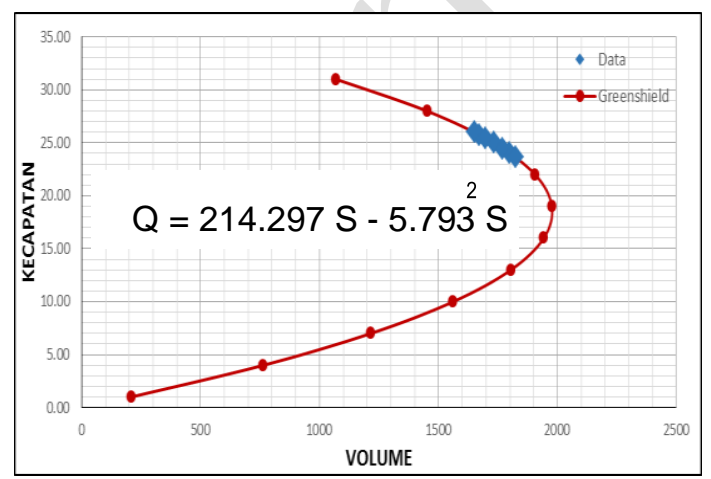

Gambar 4.5 : Grafik Hubungan antara Kecepatan dan Volume di lokasi penelitian (Jl. Dr. Ratulangi)

Kepadatan maksimum dapat dihitung dengan menggunakan persamaan (12) berikut ini :

$$
\begin{aligned}
& \mathrm{D}_{\mathrm{m}}=\frac{D_{j}}{2}=\frac{214.297}{2} \\
& \mathrm{D}_{\mathrm{m}}=\mathbf{1 0 7 . 1 4 8 \mathrm { km } / \mathrm { jam }}
\end{aligned}
$$

Jadi kepadatan maksimum $=107.15 \mathrm{smp} / \mathrm{km}$.

Kecepatan saat volume maksimum dapat dihitung dengan menggunakan persamaan (13) berikut ini :

$$
\begin{aligned}
& \mathrm{S}_{\mathrm{m}}=\frac{S_{f f}}{2} \\
& \mathrm{~S}_{\mathrm{m}}=\frac{36.955}{2} \\
& \mathrm{~S}_{\mathbf{m}}=18.48 \mathrm{~km} / \mathrm{jam}
\end{aligned}
$$

Sehingga kecepatan saat volume maksimum $=$ $18.48 \mathrm{~km} / \mathrm{jam}$

Volume maksimum dapat dihitung dengan menggunakan persamaan (14) berikut ini:

$$
\begin{aligned}
\mathrm{V}_{\mathrm{m}} & =\frac{D_{i} \cdot S_{f f}}{4} \\
& =\frac{214.297 \times 36.955}{4} \\
\mathbf{V}_{\mathbf{m}} & =\mathbf{1 9 7 9 . 8 2} \text { smp/jam }
\end{aligned}
$$

\section{KESIMPULAN DAN SARAN}

\subsection{Kesimpulan}

Adapun kesimpulan dari penelitian adalah sebagai berikut :

1. Volume arus kendaraan tertinggi terjadi pada hari Senin, pukul 14.00-15.00 wita sebesar 2245 smp/jam.

2. Kecepatan rata-rata dari setiap jenis kendaraan $25.24 \mathrm{~km} / \mathrm{jam}$, kecepatan maksimum sebesar $26.74 \mathrm{~km} / \mathrm{jam}$ dan kecepatan minimumnya sebesar 22.97 $\mathrm{km} / \mathrm{jam}$.

3. Kepadatan rata-rata ruas jalan sebesar 49,79 smp/km

4. Untuk perencanaan lalu lintas dapat menggunakan metode Greenshields dengan hubungan antara volume, kecepatan dan kepadatan dengan menggunakan adalah sebagai berikut: 


\section{DynamicSainT}

Jilid. IV No. 2., Oktober 2019

- Hubungan antara volume dan kepadatan $: \mathrm{Q}=30.766 \mathrm{D}-0.081 \mathrm{D}^{2}$

- Hubungan antara kecepatan dan kepadatan : $\mathrm{S}=30.766-0.081 \mathrm{D}$

- Hubungan antara kecepatan dan volume : $377.144-12.258 \mathrm{~S}^{2}$

\subsection{Saran}

1. Dibutuhkan data pengamatan/survey yang lebih banyak sehingga memberikan hasil lebih mendekati kenyataan.

2. Membuat analisis hubungan antara volume, kecepatan dan kepadatan dengan metode lain sebagai pembanding.

\section{DAFTAR PUSTAKA}

1. 1997, Manual Kapasitas Jalan Indonesia, Dirjen Bina Marga, Jakarta.

2. Morlok, E. K, 1984, Pengantar Teknik dan Perencanaan Transportasi, Erlangga, Jakarta.

3. Putranto, Leksmono Suryo, 2016, Rekayasa Lalu Lintas, Indeks, Jakarta.

4. Tamin, Ofyar Z., 2008, Perencanaan dan Pemodelan Transportasi, Penerbit ITB, Bandung 